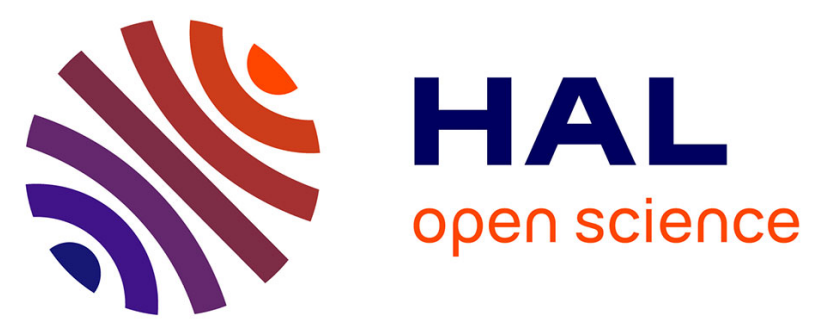

\title{
EVOLUTION OF THE FUSION LIKE PROCESS AROUND THE FERMI ENERGY
}

E. Pollacco, J. Alarja, Y. Cassagnou, B. Chambon, B. Cheynis, M. Conjeaud, R. Dayras, A. Douchy, D. Drain, A. Giorni, et al.

\section{- To cite this version:}

E. Pollacco, J. Alarja, Y. Cassagnou, B. Chambon, B. Cheynis, et al.. EVOLUTION OF THE FUSION LIKE PROCESS AROUND THE FERMI ENERGY. International Conference on Heavy Ion Nuclear Collisions in the Fermi Energy Domain, 1986, Caen, France. pp.C4-377-C4-380, 10.1051/jphyscol:1986443 . jpa-00225809

\section{HAL Id: jpa-00225809 https://hal.science/jpa-00225809}

Submitted on 1 Jan 1986

HAL is a multi-disciplinary open access archive for the deposit and dissemination of scientific research documents, whether they are published or not. The documents may come from teaching and research institutions in France or abroad, or from public or private research centers.
L'archive ouverte pluridisciplinaire HAL, est destinée au dépôt et à la diffusion de documents scientifiques de niveau recherche, publiés ou non, émanant des établissements d'enseignement et de recherche français ou étrangers, des laboratoires publics ou privés. 
EVOLUTION OF THE FUSION LIKE PROCESS AROUND THE FERMI ENERGY

E.c. pollacco , J. alarja*, y. Cassagnou*, B. Chambon** , B. CHEYNIS*", M. CONJEAUd* ${ }^{*}$, R. DAYRAS*, A. DOUCHY" , D. DRAIN** , A. GIORNI* J. GOMEZ DEL CAMPO+* * S. HARAR*, R. LEGRAIN* C. MORAND*, J.B. VIANO" and C. VOLANT'

+Service de Physique Nucléaire, Basse Energie, CEN-Saclay, F-91191 Gif-sur-Yvette Cedex, France

- Institut des Sciences Nucleaires, $\dot{F}-38026$ Grenoble, France

- Institut de Physique Nucléaire. Université claude Bernard, Lyon I, F-69622 Villeurbanne Cedex

" "Oak Ridge National Laboratory, Oak Ridge, TN 37831, U.S.A.

Résumé - L'étude des résidus d'évaporation du système $\mathrm{Ne}+\mathrm{Ag}$ montre un changement qualitatif dans le mécanisme de réaction aux alentours de l'énergie de Fermi. A $20 \mathrm{MeV} / u$ le projectile est essentílellement absorbé par la cible tandis qu'a $30-37 \mathrm{MeV} / \mathrm{u}$ on observe un transfert de masse continu accompagné d'un grand moment transverse.

Abstact - The study of evaporation residue from the $\mathrm{Ne}+$ Ag system shows that there is qualitative change in the reaction mechanism in the Fermi energy domain. At. $20 \mathrm{MeV} / \mathrm{u}$ the projectile is mostiy absobered by the target, while at 30-37 MeV/u a continious range of mass transfer with a large transverse momentum is observed.

Investigation of the evaporation residue after collisions involving large momentum transfers plays an important role in the determining the change in the reaction mechanism in the Fermi energy domain.

The reaction $20 \mathrm{Ne}+\mathrm{Ag}$ at 20,30 and $37 \mathrm{MeV} / \mathrm{u}$ was studied using the SARA facility. The evaporation residues were detected using a time of flight consisting of a MCP system and a triple detector telescope to give a flight path of $42 \mathrm{~cm}$. Recoil mass versus velocity spectra were measured for angles between $4^{\circ}$ and $35^{\circ}$, relative to the beam axis. The contour plot for the velocity as a function of mass is shown in fig. 1. As seen, the majority of the events in the choosen velocity region consists mainly of residus which are characterised by their mass ( $100 \mathrm{amu}$ ). These events are easily discriminated against fission and low energy projectile like fragments. Of interest is that at $30 \mathrm{MeV} / \mathrm{u}$, a large fraction of the events lie below the compound nucleus velocity $\mathrm{V}_{\mathrm{CN}}$.

The mass projection at 20,30 and $37 \mathrm{MeV} / \mathrm{u}$ are essentially Gaussian in shape and have mean values of 106,100 and 95 amu respectively. This suggests that the overall excitation energy, $E^{*}$ increases with bombarding energy. In fact using mean values of the invariant velocity spectra $(V>0.4 \mathrm{~cm} / \mathrm{ns})$ and the massive transfer description gives an increase of approximatly $100 \mathrm{MeV}$ in $\mathrm{E}^{*}$ between 20 and $37 \mathrm{MeV} / \mathrm{u}$.

In fig. 2 the invariant velocity spectra at the three energies are superimposed. At $20 \mathrm{MeV} / \mathrm{u}$ the spectrum shows a peak corresponding to $70 \%$ of $v_{C N}$, which in a massive 


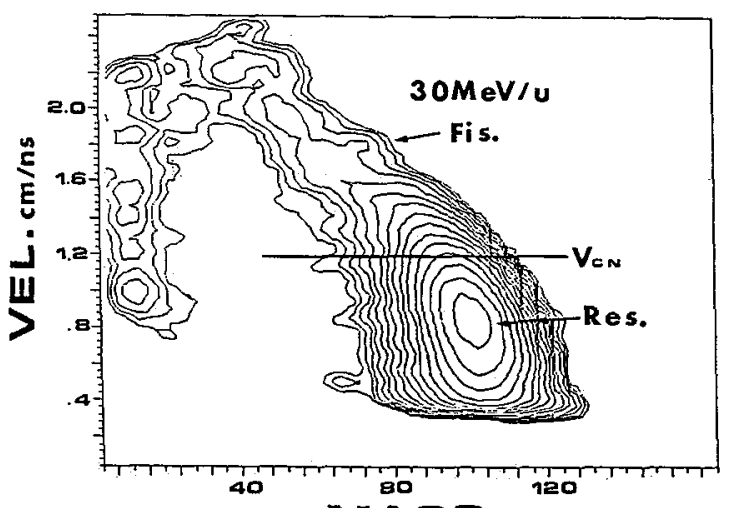

MASS amu

Fig. 1 - Mass vs velocity spectrum at $10^{\circ}$.

transfer picture translates into 14 amu being embedded into the target. What is singularly interesting is that increasing the energy to 30 $\mathrm{MeV} / \mathrm{u}$ leaves only a minor evidence of this peak. At $37 \mathrm{MeV} / \mathrm{u}$ the peak disappears completely. The same description is shown when plotting the invariant cross section in a parallel versus perpendicular velocity plane (fig. 3). Again a strong source is present at $20 \mathrm{MeV} / \mathrm{u}$, while at $30 \mathrm{MeV} / \mathrm{u}$ the events are spread over a large range of sources.

Before dealing with the angular distribution it will be pertinent to remark that comparing the $20 \mathrm{MeV} / \mathrm{u}$ with other systems, namely $160+\mathrm{Al}$, $\mathrm{Ca}, \mathrm{Ni}$ at different energies $/ 1 /$ shows, in a Viola plot that the $\mathrm{Ne}$ data is approximatly $12 \%$ below the trend.

The angular distributions were obtained by integrating the evaporation residue events for velocities larger then $0.4 \mathrm{~cm} / \mathrm{ns}$ and are presented in fig. 4. Again there exists a strong difference between 20 and $30 \mathrm{MeV} / \mathrm{u}$ and strickingly enough little change between 30 and 37 $\mathrm{MeV} / \mathrm{u}$. Thus at $20 \mathrm{MeV} / \mathrm{u}$ the events are concentreted in the forward angles as expected from a quasi-full momentum transfer process. At 30 and $37 \mathrm{MeV} / \mathrm{u}$ the data is shifted to large angles and implies that a strong transverse momentum

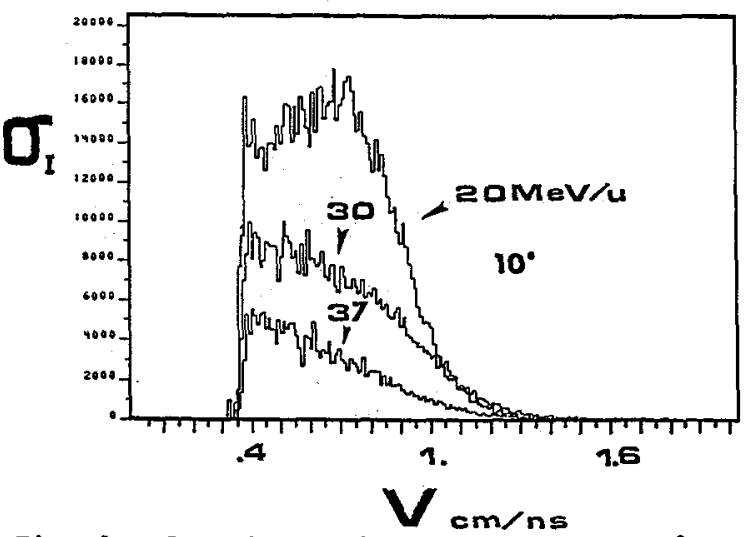

- Invariant velocity spectra at $10^{\circ}$ for $20 \mathrm{Ne}+\mathrm{Ag}$ at $20,30,37 \mathrm{MeV} / \mathrm{u})$.
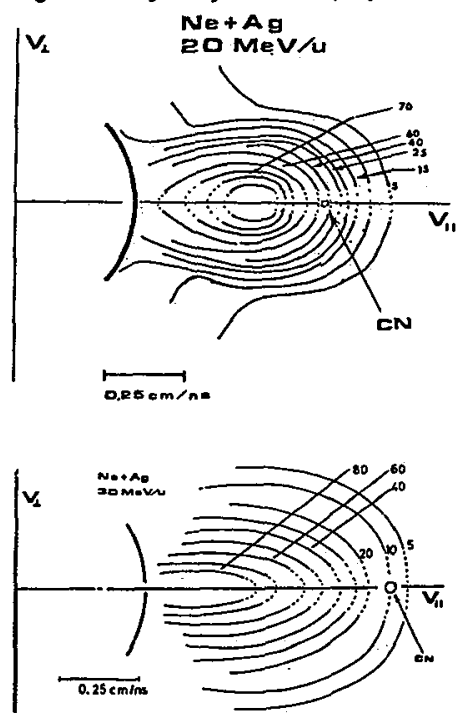

Fig. 3 - Invariant velocity contour plots. 
is present. To investigate further the distributions the same data was plotted for different velocity gates and given fig. 5 . At $20 \mathrm{MeV} / \mathrm{u}$ as clearly seen, the shape is essentially independent of velocity and with the maximum in the distribution remaining stationary with velocity window. Again the $30 \mathrm{MeV} / \mathrm{u}$ data is quite different. With the low velocity window, the distribution is very wide and the maximum lies at large angle. The most probable angle decreases with increasing recoil velocity, an effect which is strongly reminescent of two body processes. Namely, the more mass is transfered the larger is the focussing in the distribution.

In order to investigate the effects of the statistical evaporation in the angular distribution two calculations were performed. The first case assumed a complete fusion followed by 9 fast nucleons with angular distributions and temperature given by the code written by $\mathrm{B} 1$ ann $/ 2$ / (using 20 excitons) (1). The remaining energy is removed by normal light particle emission. In the second example (2) 12 nucleons are assumed to fuse with the target with the remaining assumed to escape at $0^{\circ}$ with beam velocity. The excess energy is then removed by allowing evaporation of fragments up to $Z=14$. The calculated distribution of evaporated masses give a reasonable description to the evaporative component measured by $Y$. Cassagnou et al./3/ for the same system and energy. The calculation are given in fig. 6 and show that the data 10.8 $0.9 \mathrm{~cm} / \mathrm{ns}$ ) have a considerably larger width. Thus fast particles and evaporation do not reproduce the width and thus large transverse momentum, such as two-body processes is required to explane the data.

To summarize the data at $20 \mathrm{MeV} / \mathrm{u}$ shows that the projectile is mostly absorbed by the target. At 30-37 MeV/u there is a continuous range of mass transfers and large transverse momentum. Hence a change in reaction mechanisms in the formation of residues is present between 20 and $30 \mathrm{MeV} / \mathrm{u}$.

\section{REFERENCES}

11) Chan, Y. et al., Phys. Rev. C27 (1983) 447.

/2J Blann, M., Phys. Rev. C31 (1985) 1245.

/3/ Cassagnou, Y. et al., to be published.

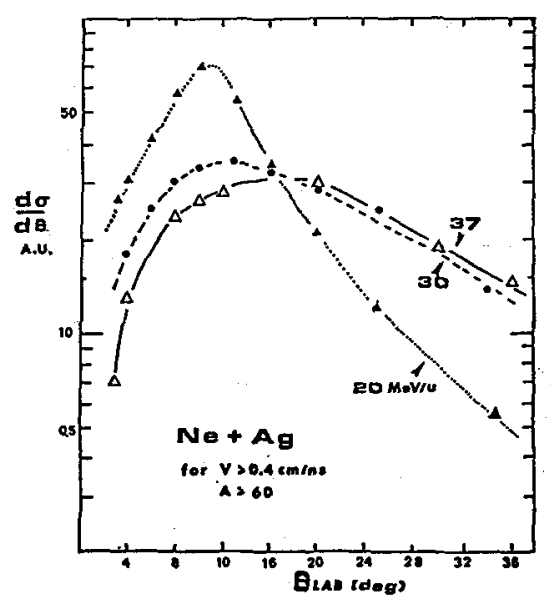

Fig. 4 - Residue angular distributions for ${ }^{20} \mathrm{Ne}$ + Ag at 20,30 and $37 \mathrm{MeV} / \mathrm{u}$. 

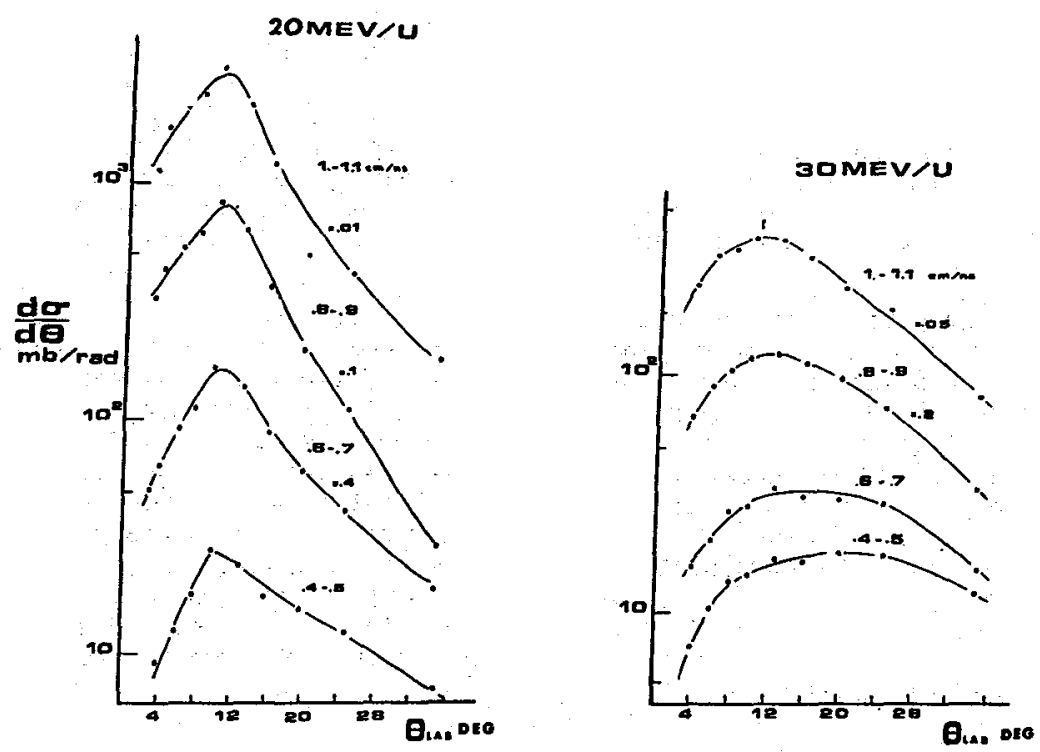

Fig. 5-Residue angular distribution gated by the velocity.

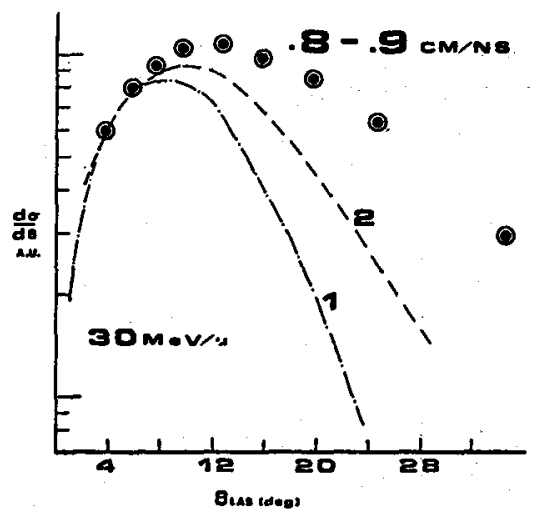

Fig. 6 - See text. 